\title{
NORTHWARD EXTENSION OF EURASIAN COLLARED-DOVE IN SASKATCHEWAN
}

\author{
C. STUART HOUSTON, 863 University Drive, Saskatoon SK S7N 0J8, and BOB \\ LUTERBACH, 2644 Shooter Drive East, Regina SK S4V 1E1
}

The Eurasian Collared-Dove was first released on this side of the Atlantic on New Providence island, in the Bahamas, in the mid-1970s. It spread with unprecedented speed across the North American continent, facilitated by the availability of bird seed at backyard feeders. " It resides almost exclusively near human habitations, making it readily observable by backyard birders.

Until recently, this species was not shown in standard field guides, and since the Ringed Turtle-Dove has a similar black "collar" (in both species, the "collar" line is less prominent in young birds), initial sightings in Saskatchewan were first assumed to be escaped domesticated TurtleDoves (see note at end of article). The Eurasian Collared-Dove is larger than the Ringed Turtle-Dove, with gray rather than white vent-feathers and darker wing tips. The Collared-Dove has a three-note call, rather than the two-note call of the TurtleDove.

\section{First Saskatchewan records}

In retrospect, it seems probable that the "Ringed Turtle-Dove" sighted in the backyard at 301 Second Street, Langham, from about June 10 to 29, 1998, moving between there and Dieter Martin's greenhouse, was Saskatchewan's first Eurasian Collared-Dove. The location of this sighting was reported on the Saskatoon Rare Bird Alert. Also in 1998, a pair of Collared-Doves was seen by Al Smith at Last Mountain Regional Park west of Govan on 24 August and 5 October. ${ }^{12}$
In 1999, there were three sightings in Saskatchewan. In Weyburn, in April, ' John Whitell saw a pair of unusual doves which were not positively identified as Eurasian Collared-Doves until November 18. In Regina, a pair started to frequent the feeding station of Audrey and Ian Traquair on September 30, where conclusive photographs were obtained. The third sighting was by Paul Geraghty, and Don and Lyn Robertson, at Avonlea on November 6 . All five birds stayed through early winter, with the Weyburn and Regina pair representing a new Christmas Bird Count (CBC) species for Saskatchewan. ${ }^{8}$

Eurasian Collared-Dove sightings on CBCs have occurred each year since 1999: in 2000, one bird at Regina and one in count period at Moose Jaw; in 2001, eight birds in Moose Jaw and one seen during count period in Grasslands National Park; in 2002, four in Swift Current and one at Eastend; in 2003, eight at Swift Current. ${ }^{9}, 10,13,14$ Clearly, where present, this is a year-round species.

\section{Breeding records}

In the village of Mortlach, which has become the Collared-Dove capital of Saskatchewan, the first bird seen established residence in the yard of Don and Mary Flack on June 4, 2001, and a pair was seen copulating there in July. ${ }^{2}$ Numbers increased to four birds by late July and seven on October 7. Mary Flack titled this the "Eurasian invasion"? 
On June 25, 2002, Bob Luterbach found a nest containing a squab, about $8 \mathrm{~m}$ above ground in a spruce in Ed Jaeger's yard, two blocks west of the Flack home. This was the first confirmed breeding record for Saskatchewan. Ed had suspected the presence of the nest, but the adult was immobile on the nest and blended into the grey sky. During a thunderstorm on June 30 , the flimsy nest blew out of the tree and an almost-fledged nestling perished. ${ }^{3}$ On September 30, two adults were seen feeding a late fledging juvenile, presumably the result of a second nesting. ${ }^{4}$ Although they lay only two eggs per clutch, CollaredDoves often make two or three (up to six in Europe) nest attempts each year. In Mortlach, the nests inspected were made of grass. Ed feeds the doves year-round, chiefly black oil sunflower seeds on the ground, and provides open water in the form of an electric heater in a dog dish.

In the spring of 2003, there were eight doves in Mortlach. One was killed by a cat. That summer, there were three nests in the village. Two nests were found in July, about
$9 \mathrm{~m}$ above ground, in the dense top branches of adjacent spruce trees, $3 \mathrm{~m}$ apart, in $\mathrm{Ed}$ Jaeger's yard. One of the nests was in the tree that had the nest the previous year. The third nest was in a tall spruce in a deserted yard, halfway between Flack's and Jaeger's. By October 30, 13 Collared-Doves were present in Mortlach.

\section{New Localities}

There were sightings in several new locations in 2003. On May 18, Daniel Sawatzky saw a bird at the eastern edge of Swift Current carrying what looked like a fecal sac, possible evidence of breeding. ${ }^{5} \mathrm{~A}$ single bird appeared in the yard of Lorne Rowell in Fort Qu'Appelle about 10 September (Lorne Rowell, pers. comm.) and remained there until early November.

In Laird, on a cold, stormy spring day, May 3, 2003, a pair of Collared-Doves appeared on the ground, eating corn and sunflower seeds, at the home of Alice and Arly Nickel. One of these may have been the bird seen over Christmas and for most of the winter at the Gary and Pearl Bergen

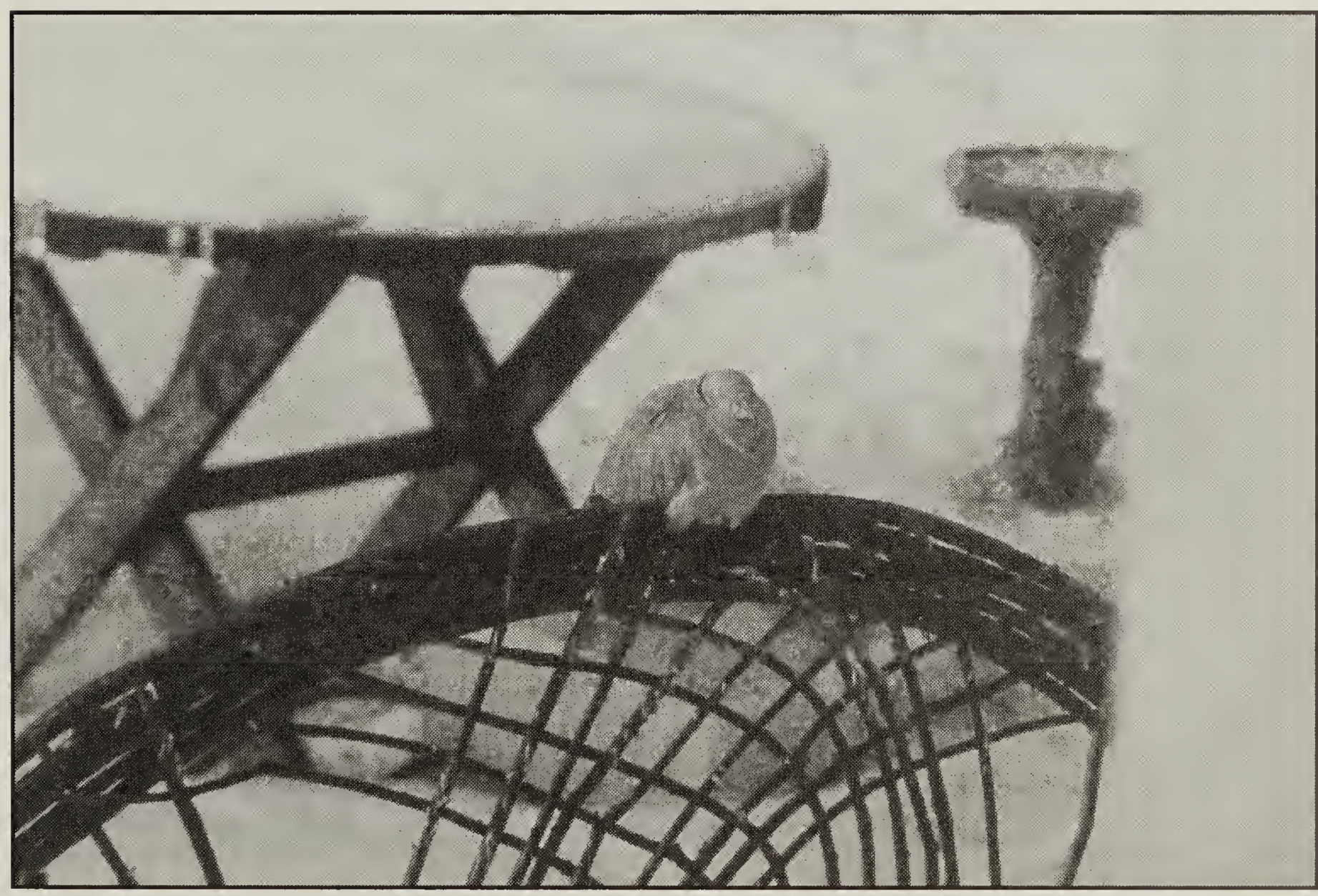

Figure 1. Eurasian Collared-Dove near Laird, SK

Pearl Bergen 
farm, $1.6 \mathrm{~km}$ north and $4 \mathrm{~km}$ west of Laird (Figure 1). It ate bird seed from a bag on the Bergen picnic table.

The Laird pair soon built a nest across the street, $7.3 \mathrm{~m}$ above ground in the crotch of an American Elm. Incubation (normally 15 days) and brooding (normally for eight days) was continuous from May 13 until June 4. The single, half-grown young was banded on June 7 by CSH, the first banding of this species in Saskatchewan.

The pair then moved back across the street, to nest $3.6 \mathrm{~m}$ above ground in a Manchurian Elm in the Nickel yard. The second nest contained two eggs on July 2 and two tiny young on July 7 . The young, estimated to be five days old, were too small to band on July 10 . On July 14, after a wind and rain storm, one young was dead in the nest and the other was missing. The adult pair continued to visit the Nickel feeding tray almost every day through the winter, eating cracked corn, cracked wheat, and sunflower seeds, and surviving $-46^{\circ} \mathrm{C}$ temperatures.

The first Eurasian Collared-Dove in the Saskatoon Bird Area was seen on June 30 by fifteen observers during a Saskatoon Nature Society excursion to Blackstrap Lake. ${ }^{5}$ On July 17, Margaret Madsen reported a pair of Collared-Doves flying to and from the top of a large spruce in a residential area of Delisle. David Miller climbed up to the nest, $11.6 \mathrm{~m}$ above ground. Although it was empty, with no sign of young, this nest is the first presumptive breeding record for the Saskatoon Bird Area.

The short tarsus of the Collared Dove necessitates banding with "shorter" bands. $\mathrm{CSH}$ has a supply and would appreciate hearing of additional nests next year.

Note: Ringed Turtle-Doves, although they carry the scientific name, Streptopelia risoria, are not a full species but a domesticbred variant of the African Turtle-Dove,
Streptopelia roseogrisea. The name "Ringed Turtle-Dove," and the scientific name, were applied in 1916 by Robert Ridgway to feral populations of aviary birds descended from African Turtle-Doves and living on several Caribbean Islands. ${ }^{15}$

Acknowledgements: This article would not have been possible without the assistance of Mary Flack, Ed Jaeger, Alice Nickel, Lorne Rowell and Al Smith.

1. BAILEY, M. 2000. The history of Collared-Doves in Weyburn, Saskatchewan. Blue Jay 58:150-151.

2. BAIN, M. 2001. Cross Canada round-up. Birders Journal 10:218-237.

3. BAIN, M. 2002a. Cross Canada round-up. Birders Journal 11:118-138.

4. BAIN, M. 2002b. Cross Canada round-up. Birders Journal 11:162-182.

5. BAIN, M. 2003a. Cross Canada round-up. Birders Journal 12:92-110.

6. BAIN, M. 2003b. Cross Canada round-up. Birders Journal 12:134-156.

7. FLACK, M. 2001. Mortlach's Eurasian invasion. Blue Jay 59:208.

8. HARRIS, W.C. 2000. 58th annual Saskatchewan Christmas Bird Count, 1999. Blue Jay 58:2-28.

9. HARRIS, W.C. 2001. 59th annual Saskatchewan Christmas Bird Count, 2000. Blue Jay 59:2-28.

10. HARRIS, W.C. 2002. $60^{\text {th }}$ annual Saskatchewan Christmas Bird Count, 2001. Blue Jay 60:2-28.

11. ROMAGOZA, C.M. 2002. Eurasian Collared-Dove (Streptopila decaocto). In The Birds of North America, No. 630 (A. Poole and F. Gill, eds.). The Birds of North America, Inc., Philadelphia, PA.

12. SMITH, A.R. 2002. Last Mountain Bird Observatory: 10-year summary, 1990-1999. Can. Wildl. Serv., Saskatoon. 56 pp.

13. SMITH, A.R., and R.E. JOHANSON. 2003. $61 \mathrm{st}$ annual Saskatchewan Christmas Bird Count, 2002. Blue Jay 61:2-26.

14. SMITH, A.R., and R.E. JOHANSON. 2004. $62^{\text {nd }}$ annual Saskatchewan Christmas Bird Count, 2003. Blue Jay 62:2-23

15. SMITH, P.W. 1987. The Eurasian Collared-Dove arrives in the Americas. American Birds 41:13791391.

Blue Jay 